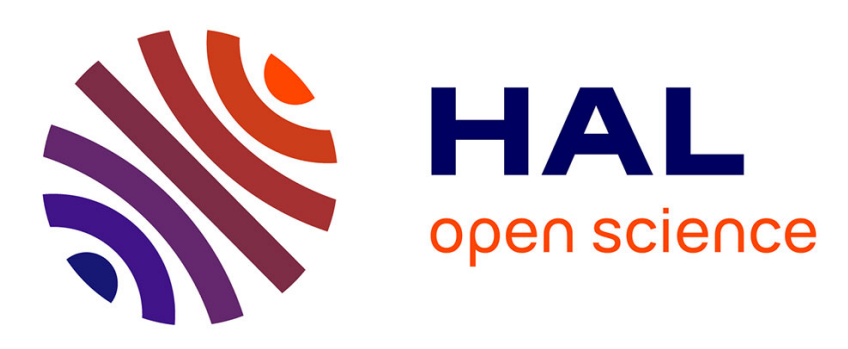

\title{
Iterative method to analyze the flow behavior around a cavitating hydrofoil
}

Adjali Saadia, Yahiaoui Tayeb, Belkadi Mustapha, Jean Marc Laurens

\section{To cite this version:}

Adjali Saadia, Yahiaoui Tayeb, Belkadi Mustapha, Jean Marc Laurens. Iterative method to analyze the flow behavior around a cavitating hydrofoil. Journal of Flow Visualization and Image Processing, 2019, 26 (2), pp.185-207. 10.1615/JFlowVisImageProc.2019030191 . hal-02354322

\section{HAL Id: hal-02354322 \\ https://hal-ensta-bretagne.archives-ouvertes.fr/hal-02354322}

Submitted on 18 Oct 2021

HAL is a multi-disciplinary open access archive for the deposit and dissemination of scientific research documents, whether they are published or not. The documents may come from teaching and research institutions in France or abroad, or from public or private research centers.
L'archive ouverte pluridisciplinaire HAL, est destinée au dépôt et à la diffusion de documents scientifiques de niveau recherche, publiés ou non, émanant des établissements d'enseignement et de recherche français ou étrangers, des laboratoires publics ou privés.

\section{(c)(1)}

Distributed under a Creative Commons Attribution| 4.0 International License 


\title{
ITERATIVE METHOD TO ANALYZE THE FLOW BEHAVIOR AROUND SUPERCAVITATING HYDROFOIL
}

\author{
Adjali Saadia, ${ }^{1}$ Yahiaoui Tayeb, ${ }^{2,}$ Belkadi Mustapha, ${ }^{1}$ \\ $\mathcal{E}$ Jean Marc Laurens ${ }^{3}$ \\ ${ }^{1}$ Laboratoire d'Aéro-Hydrodynamique Naval, Département de Génie Maritime, \\ Université des Sciences et de la Technologie d'Oran Mohamed Boudiaf, \\ USTO-MB, Oran, Algérie \\ ${ }^{2}$ Laboratoire d'Aéronautique et Systèmes Propulsifs, Département de Génie \\ Mécanique, Université des Sciences et de la Technologie d'Oran Mohamed \\ Boudiaf, USTO-MB, Oran, Algérie \\ ${ }^{3}$ Brest University, ENSTA Bretagne, 2 Rue François Verny, 29806 Brest, Cedex \\ 9 la France
}

In this article, we present the results of numerical simulations of $2 D N A C A$ profiles advancing at constant velocities close to the free surface. First, we use a NACA0012 hydrofoil section and compare our results with those of the famous Duncan experiment in order to validate our simulation methodology. Then, a NACA0015 hydrofoil was used at different immersion depths. We confirm that the lift increases as we approach the free surface until breaking waves were generated. Then we perform flow simulations in the presence of sheet cavitation at the suction side of the profile with a different number of cavitations. After that, using an iterative procedure, we combine the free surface and sheet cavitation effects on the NACA16-006 hydrofoil for different cavitation numbers at the critical depth. Finally a supercavitating foil is tested with our procedure. As expected, the lift increases as the cavitation number is decreasing.

KEY WORDS: breaking waves, cavitation, free surface, hydrofoil, VOF

\section{INTRODUCTION}

Cavitation is a particular two-phase flow with a transition phase (vaporization/condensation) driven by a pressure change without any heating. It can be interpreted as the rupture of the liquid continuum due to excessive stresses. The modeling cavitation flows as a multifluid is a complex problem especially with free surface effect. $\mathrm{Nu}$ - 


\section{NOMENCLATURE}

\begin{tabular}{llll}
$c$ & chord length of the hydrofoil & Re & \multicolumn{1}{c}{ Reynolds number } \\
CD & drag coefficient & Greek Symbols \\
CL & lift coefficient & $\alpha_{\mathrm{a}}$ & volume fraction of air \\
$C p$ & pressure coefficient & $\alpha_{\mathrm{V}}$ & volume fraction of vapor \\
$\mathrm{Fr}$ & Froude number & $\alpha_{\mathrm{L}}$ & volume fraction of water \\
$g$ & gravity & $\mu_{\mathrm{t}}$ & turbulent viscosity \\
$h$ & submergence height & $\rho_{\mathrm{a}}$ & density of air \\
$P_{\text {op }}$ & operating pressure & $\rho_{\mathrm{w}}$ & density of water \\
$P_{\text {sat }}$ & pressure of saturation & $\sigma$ & cavitation number
\end{tabular}

merical prediction of wave pattern, lift force, and drag force of submerged hydrofoil is carried out. Giesing and Smith (1967) adopted the Kelvin source-type complex potential to satisfy the Neumann-type body boundary condition and linearized free surface condition to solve 2D hydrofoil potential flow. Duncan et al. (1983) carried out experiments for the NACA0012 hydrofoil for various submergence depths, angles of attack, and velocities; they obtained free surface wave elevation. Hino et al. (1993) introduced the finite volume method with an unstructured grid for free surface flow simulation which was based on the Euler equations. Farmer et al. (1994) and Muzaferija and Perie (1997) developed methods for computation of free surface that were applied successfully. When a hydrofoil is close enough to the free surface and its velocity exceeds a certain level, the generated waves at the free surface can be smooth or may undergo breaking. When the hydrofoil moves at a constant speed, the smooth waves are usually steady, and the breaking waves can be both quasi-steady and fully unsteady. Kwag (2000) used the finite volume method with unstructured meshes and an interface capturing scheme to determine the shape of the free surface. The linear equations are solved by conjugating gradient type-solvers, and the nonlinearity of equations is accounted for through Picard iterations.

Xie and Vassalos (2007) developed a potential-based panel method to determine the steady potential flow of three-dimensional hydrofoil under the free surface. The method used constant-strength doublets and source density distribution over the foil body surface. The Dirichlet-type boundary condition is used instead of a Neumann-type condition. Tarafder et al. (2010) developed a numerical scheme for analyzing the potential flow around the 3D hydrofoil by the combined source and doublet panel method based on the Dirichlet boundary condition without taking into account the free surface effect. 
The performance analysis for hydrofoil at different submergence depths is one of the important subjects in basic hydrodynamics that attracted attention of a number of researchers. Mashud et al. (2014) applied the VOF method to solve the fluid equations with a free surface. The standard $k-\varepsilon$ turbulence model was used for turbulent flow around a hydrofoil at different submergence depth ratios. The two-dimensional implicit finite volume method (FVM) is applied to solve the Reynolds-averaged Navier-Stokes (RANS) equation, the analysis is carried out with a NACA0015 hydrofoil for different depths ratios $h / c$. Prasad et al. (2015) presented a numerical simulation of unsteady flows with a free surface. A finite volume method is used with the interface capturing a volume of fluid (VOF) to solve the fluid equations in motion. The $k-\varepsilon$ model is used for simulating the turbulent flow around a shallowly submerged hydrofoil. The study is done for different submergence depths.

The cavitation with the effect of free surface plays a major role in surface sea-going vessel design and operation as well as in propellers and hydrofoil. Many approaches have been developed during the last time. Merkle et al. (1998) and Kunz et al. (2000) used different mass transfer models based on semianalytical equations. Li et al. (2010) simulated cavitating flow around the NACA0015 hydrofoil using the model of cavitation developed by Schnerr and Sauer (2001). Singhal et al. (2002) developed the full cavitation model which assumes the working fluid to be a mixture of a liquid, liquid vapor, and of a noncondensable gas. Dular et al. (2005) used a new technique where the PIV method is combined with the LIF technique to experimentally determine the instantaneous and average velocity and void ratio fields (cavity shapes) around the hydrofoils. An experimental and numerical study of developed cavitating flow was performed for ALE15 and ALE25. The velocity in the reference plane upstream of the hydrofoil is verified by the LDA (Laser Doppler Anemometry) method. Asnaghi et al. (2010) used the bubble dynamics model which is based on the Rayleigh equation to simulate the phase change. The numerical simulation is done for unsteady cavitation around the NACA0015 hydrofoil. The finite-volume approach was written in body-fitted curvilinear coordinates to discretize 2D and 3D equations around a hydrofoil. The results obtained by Zwart et al. (2004), Kunz et al. (2000), and Singhal et al. (2002) are compared considering the flow around the NACA66 (MOD) and NACA009 hydrofoils.

Li and Terwisga (2012) investigated the flow characteristics under cavitation and noncavitation conditions on the NACA0015 hydrofoil and on a NACA0018-45 hydrofoil by the RANS code FLUENT, to predict the conditions for erosive cavitation. The study is done using the 3D unsteady two-phase RANS codes. Roohi et al. (2013) used a turbulence model and the volume of fluid (VOF) technique to simulate flow around the Clark-Y hydrofoil. The simulation is performed for the cloud and supercavitation regimes. Both steady-state and transient conditions are used in the Kunz et al. (2000) and Sauer (2000) cavitation models. Kim and Lee (2015) explored the effect of hydrophobicity on cloud cavitation. Large Eddy Simulation (LES) is used to capture 
turbulence around the Clark-Y hydrofoil, and slip strength was controlled using the friction coefficient.

However, all these studies have not yet included effects due to the free surface. In fact, Jin et al. (2013) introduced the free surface effect on the ventilated cavitation process, they used cavitation model developed by Merkle et al. (1998). More recently, $\mathrm{Wu}$ and Chen (2016) used an iteration procedure to iteratively update the free surface and the cavity surface.

The aim of this work is thus to develop a numerical procedure to compute cavitating flow with the effect of the free surface. Three cases are considered in this paper, all steps are done in Fluent without regenerating mesh, and the same mesh has been used for all iterations.

The selected numerical simulations are:

Case 1. The free surface wave generation is studied for submerged hydrofoil at different depths of submergence to compute wave's amplitudes, lift and drag forces. The VOF method is used to simulate the problem where both the fluids (air and water), first are applied to the NACA0012 hydrofoil for comparing the results with experimental results of Duncan (1983). The method is then applied to NACA0015 hydrofoil for different submergence depths to obtain the wave elevations, the values of lift and drag coefficients.

Case 2. The cavitating flows around a two-dimensional NACA0015 hydrofoil are investigated using the Schnerr and Sauer (2001) cavitation model combined with the $k-\varepsilon$ turbulence model.

Case 3. The numerical procedure is developed to compute cavitating flow with the effect of the free surface without change of mesh. In this study, the Schnerr and Sauer (2001) model is used for solving the governing equations for cavitating flow, the VOF model is used to capture free surface pattern, and the standard $k-\varepsilon$ model is employed in turbulence modeling. To solve the fluid flow, the method is applied first to the 2D NACA16-006 hydrofoil, and then to supercavitating hydrofoil with different cavitation numbers.

\section{MATHEMATICAL FORMULATIONS}

Generally, the Navier-Stokes equations are used to designate either the momentum equations or the set of momentum equations together with the continuity equation. In this paper, the term "Navier-Stokes equations" is used for the momentum equations, while the term "complete Navier-Stokes equations" is used for the momentum equations together with the continuity equation. The turbulence closure is achieved by using the $k-\varepsilon$ model.

The treatment for the free-surface flow uses an interface capturing method with the VOF technique. The VOF method originally developed by Hirt and Nichols (1981) is used to compute the surface wave caused by the submerged hydrofoil when moving 
close to the free surface of water. This model used a fixed grid technique designed for two or more immiscible fluids where the position of the interface between the fluids is part of the unknown to be found through the solution procedure.

In the VOF model, the fluids share a single set of momentum equations, and the volume fraction of each of the fluids in each computational cell is tracked throughout the domain. In this model, the following three conditions are possible:

$$
\begin{gathered}
\alpha_{L}=0, \text { the cell is empty (of liquid); } \\
\alpha_{L}=1 \text {, the cell is full (of liquid); } \\
0<\alpha_{L}<1 \text {, the cell contains liquid interface. }
\end{gathered}
$$

In the VOF method, $\alpha_{\mathrm{L}}$ is also used to determine the location of the interface. The normal direction of the interface lies in the direction in which the value of $\alpha_{L}$ changes most rapidly. The tracking of the interface is accomplished by solving the continuity equation of the volume fraction. For the coefficient $\alpha_{\mathrm{L}}$, this equation has the form

$$
\frac{\partial \alpha_{L}}{\partial t}+\nabla \alpha_{L} u=0
$$

The volume fraction equation will not be solved for air; the volume fraction of air will be computed based on the following constraint:

$$
\alpha_{\mathrm{L}}+\alpha_{\mathrm{a}}=1 .
$$

The properties appearing in the transport equations are determined by the presence of the component phases in each control volume. For example, the density in each cell is given by

$$
\rho=\rho_{\mathrm{L}} \alpha_{\mathrm{L}}+\rho_{\mathrm{a}} \alpha_{\mathrm{a}} .
$$

The viscosity is also computed in a similar manner.

A single momentum equation is solved throughout the domain, and the resulting velocity is shared among the phases. The momentum equation is dependent on the volume fractions of all phases through the properties $\mu$ and $\rho$.

\subsection{Cavitation Model}

To close the system of equations an additional transport equation is solved for $\alpha_{\mathrm{v}}$ :

$$
\frac{\partial\left(\alpha_{\mathrm{v}} \rho_{\mathrm{v}}\right)}{\partial t}+\nabla \cdot\left(\alpha_{\mathrm{v}} \rho_{\mathrm{v}} \overrightarrow{v_{m}}\right)=R_{e}-R_{c}
$$

where the source terms $R_{e}$ and $R_{c}$ are used to account for the mass transfer between phases and need to be modeled via a cavitation model.

The cavitation model proposed by Schnerr and Sauer (2001) defines the source terms $R_{e}$ and $R_{c}$ as follows: 


$$
R_{e}=\frac{\rho_{\mathrm{v}} \rho_{L}}{\rho_{m}} \alpha(1-\alpha) \frac{3}{R_{B}} \sqrt{\frac{2}{3} \frac{\left(P_{\mathrm{v}}-P\right)}{\rho_{\mathrm{L}}}},
$$

when $P_{\mathrm{v}}>P$ and

$$
R_{e}=\frac{\rho_{\mathrm{v}} \rho_{L}}{\rho_{m}} \alpha(1-\alpha) \frac{3}{R_{B}} \sqrt{\frac{2}{3} \frac{\left(P_{\mathrm{v}}-P\right)}{\rho_{\mathrm{L}}}},
$$

when $P_{\mathrm{v}}<P$.

The bubble radius can be related to the vapor volume fraction $\alpha$. The bubble radius $R_{B}$ can be determined by

$$
R_{B}=\left(\frac{\alpha}{1-\alpha} \frac{3}{4 \pi} \frac{1}{n_{0}}\right)^{1 / 3}
$$

where $n_{0}$ is the bubble number density given as a constant, the default value $n_{0}=1 e+13$ is used.

\section{NUMERICAL SIMULATIONS}

As mentioned in the previous section, three cases are considered.

\subsection{Analysis of 2D Hydrofoil under the Free Surface}

At the beginning, the VOF method is used for free surface flow around the submerged NACA0012 and NACA0015 hydrofoils at different submergence depth ratios (Case 1). The standard $k-\varepsilon$ turbulence model is used to capture turbulent flow around the hydrofoil with the free surface zone at different submergence ratios $(h / c)$. The SIMPLEC algorithm solver is selected to solve the pressure and momentum equations, which can lead to more robust calculation and faster convergence. The discretization schemes adopt second-order upwind. The different boundary conditions, viz., inlet, outlet, upper, and lower ones, are presented in Fig. 1. The lengths of the inlet and outlet boundaries are $15 c$, upper and lower boundaries are $12 c$, where $c$ is the chord length of the hydrofoil. A velocity-inlet boundary condition is applied on the upstream inflow, the velocity component is $U=0.8 \mathrm{~m} / \mathrm{s}$. A pressure-outlet boundary condition is imposed at the outlet; the symmetry boundary condition is applied for both upper and lower boundaries.

The mesh of the faces is done by quad and tetra elements throughout the domain. Figure 2 shows the unstructured grid of the computational domain. A boundary layer is generated around the profile and fine meshing is applied near the free surface as shown in Figs. 2 and 3.

First, the simulation of the NACA0012 hydrofoil is done with the same conditions as the experiment reported by Duncan (1983). The uniform flow velocity $U$ is $0.8 \mathrm{~ms}^{-1}$ 


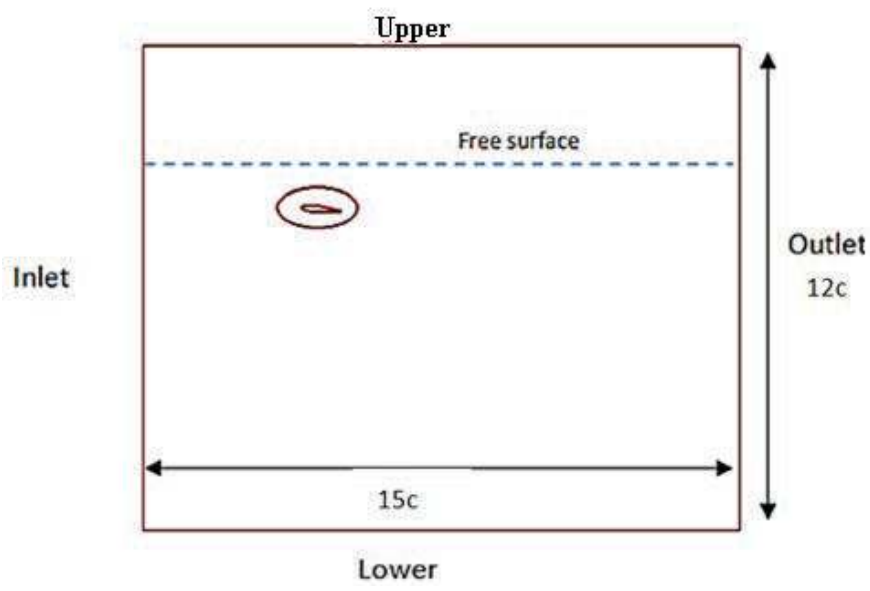

FIG. 1: Computational domain with boundaries

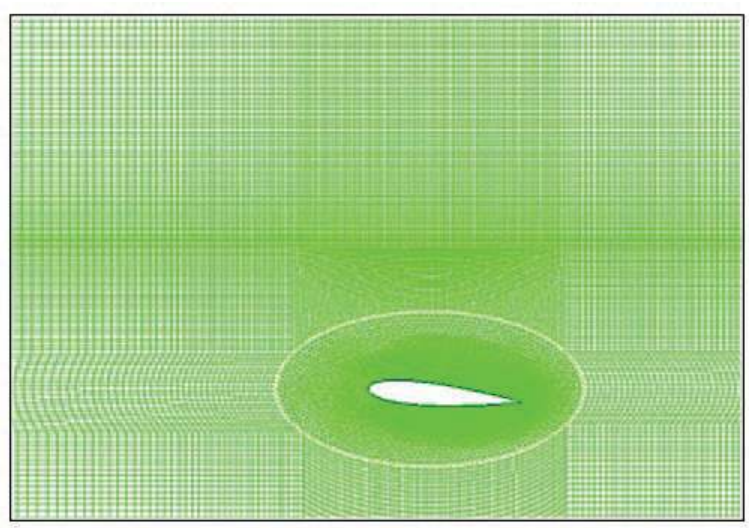

FIG. 2: Computational grid

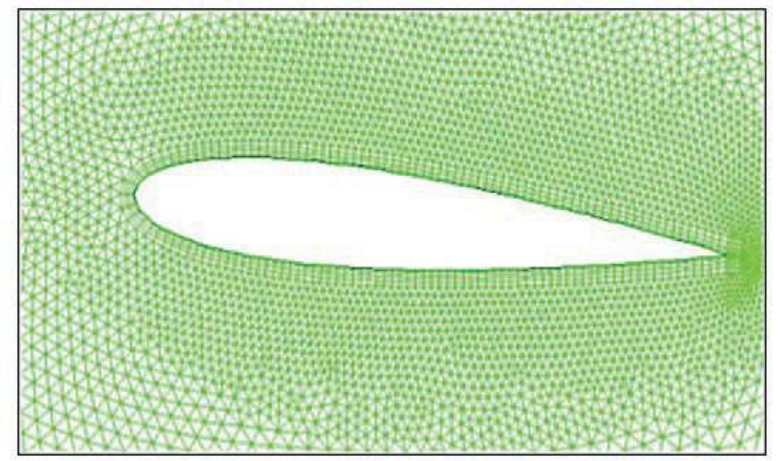

FIG. 3: Close-up view of grid around the hydrofoil 
and the chord length is $0.2 \mathrm{~m}$. For our study the Froude number is 0.571 and the Reynolds number Re is $1592 \cdot 10^{5}$. The incidence angle is set to be $5^{\circ}$.

To check the grid independence of the results, five grids, namely, Grid 1 to Grid 5 are used in this investigation. Grids $1-4$ consist of 48,981 cells, 58,806 cells, 72,659 cells, 85,294 , respectively, and Grid 5 has 92,105 cells. The computed values of lift and drag coefficients for the five grids are shown in Figs. 4 and 5. There is almost no change in the results on increase in the total number of cells from 85,294 to 92,105. Therefore, Grid 4 is used in all the calculations.

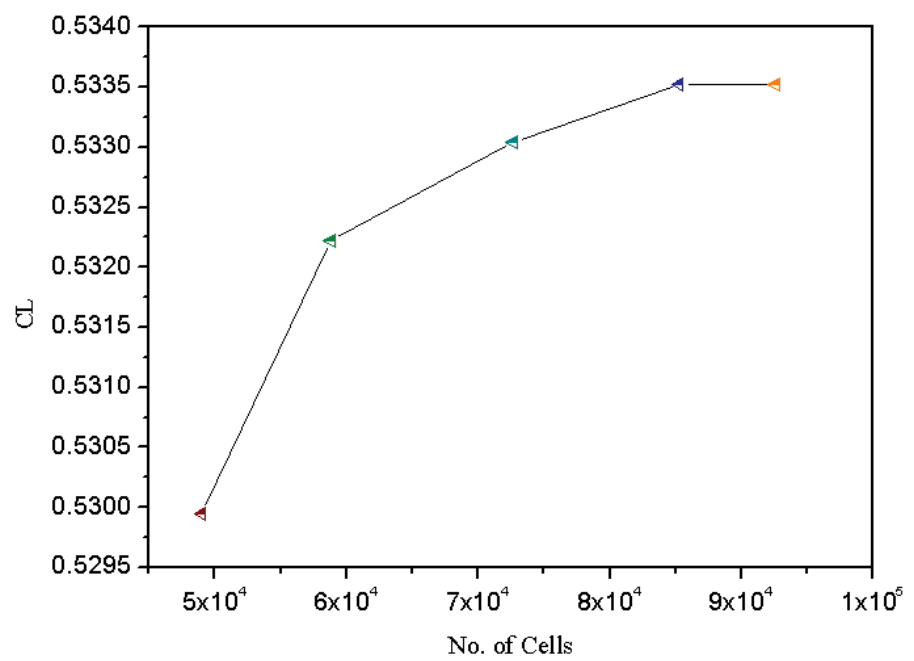

FIG. 4: Grid independence checks for lift coefficients

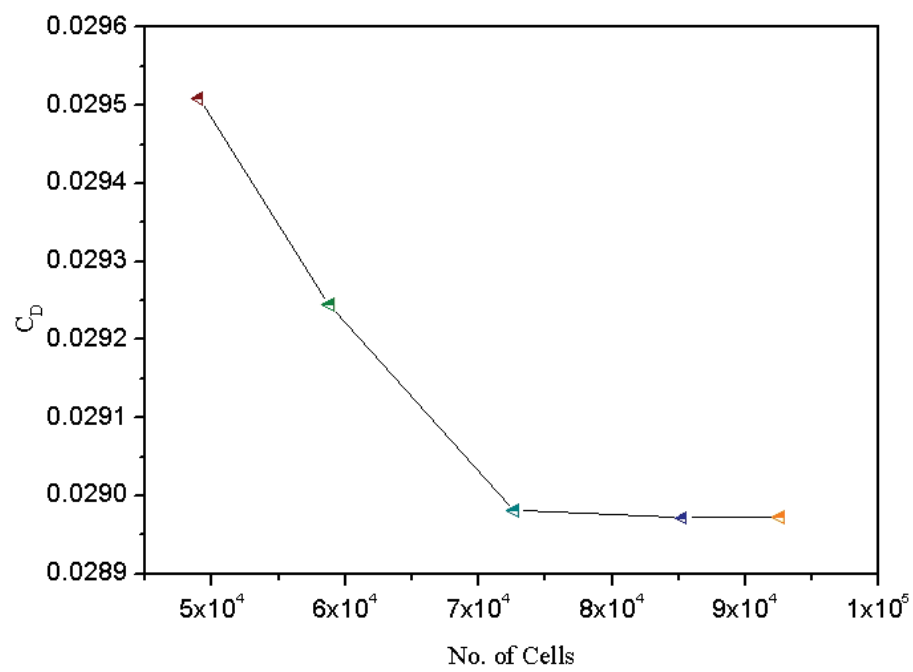

FIG. 5: Grid independence checks for drag coefficients 
Figure 6 shows the comparison between the present computational results and experimental results of Duncan (1983). From the figure, it is observed that the computed wave elevations agree well with experimental wave elevation. The computed wave amplitudes for all crests and troughs are slightly underestimated compared with Duncan's results.

The numerical simulation is then carried out for the NACA0015 hydrofoil section under the same conditions as mentioned above for different submergence depths.

The wave profiles for various depths of submergence ratio $h / c$ on the free surface are compared in Fig. 7. From this figure, it is observed that the hydrofoil comes closer

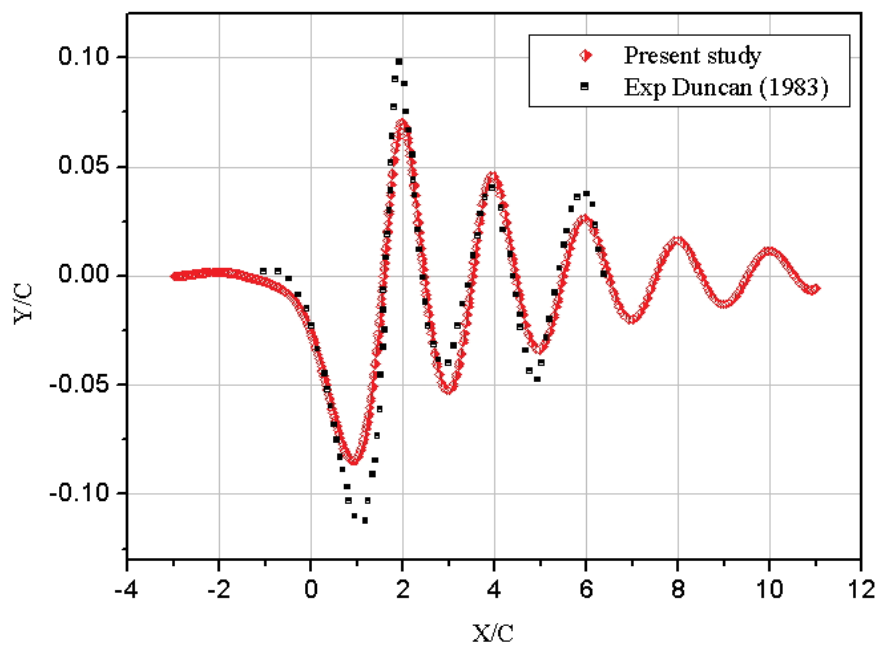

FIG. 6: Free surface elevation for the NACA 0012 hydrofoil at $h / c=0.91$

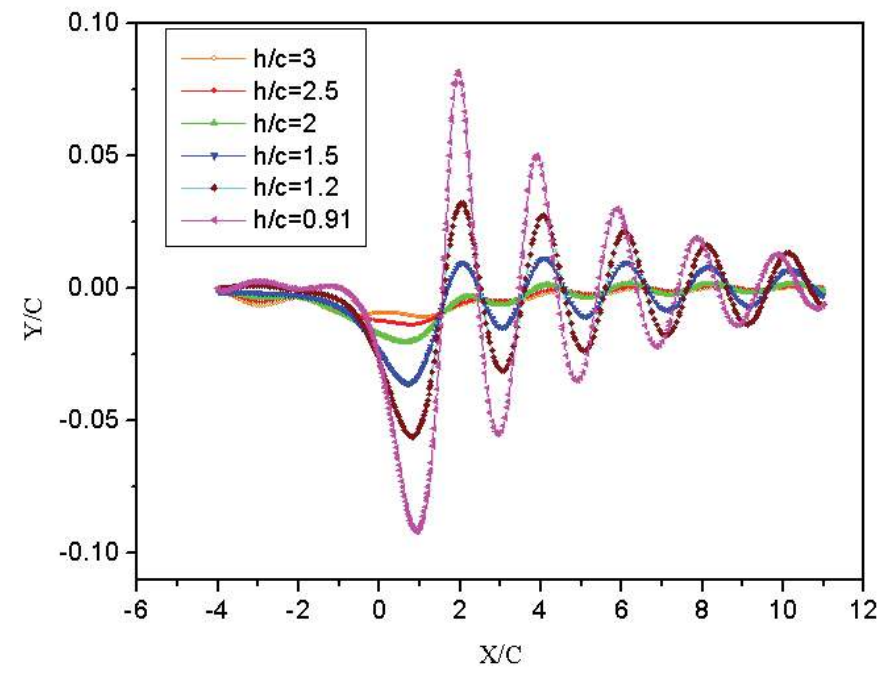

FIG. 7: Comparison of wave elevations for the NACA0015 hydrofoil at different $h / c$ ratios 
to the free surface with decrease of the submergence depths. The amplitudes of the wave crests and troughs gradually increase and the wave's length slightly decreases.

The lift and drag coefficients at an incidence angle of $5^{\circ}$ for different submergence depths are given in Table 1 . The lift and drag coefficients decrease with increase in the submergence ratio $h / c$. This interesting phenomenon occurs here since the Froude number is low (0.5711) for this study. The phenomenon is explained in detail by Faltinsen (2005). The velocity contour around the hydrofoil for submergence depths $h / c=0.91$ is shown in Fig. 8. It is observed that velocity is very high near the leading edge and then it gradually decreases towards the trailing edge of the hydrofoil. It is also observable that the velocity is smaller than the average value $(0.8 \mathrm{~m} / \mathrm{s})$ above the trough and under the crest and greater inversely under the trough and above the crest.

The contours of volume fraction are shown in Fig. 9. Some portion of water with red color moves back in air region which is also the indication of wave breaking.

TABLE 1: Force coefficients at an incidence angle of $5^{\circ}$ and $\mathrm{Fr}=0.5711$

\begin{tabular}{|c|c|c|}
\hline Submergence Depth Ratio $(\boldsymbol{h} / \boldsymbol{c})$ & Lift Coefficient $(\mathbf{C L})$ & Drag Coefficient $(\mathbf{C D})$ \\
\hline 0.91 & $5.7589 \cdot 10^{-1}$ & $3.1161 \cdot 10^{-2}$ \\
\hline 1.2 & $5.6241 \cdot 10^{-1}$ & $2.6186 \cdot 10^{-2}$ \\
\hline 1.5 & $5.5101 \cdot 10^{-1}$ & $2.4627 \cdot 10^{-2}$ \\
\hline 2 & $5.4203 \cdot 10^{-1}$ & $2.3981 \cdot 10^{-2}$ \\
\hline 2.5 & $5.3644 \cdot 10^{-1}$ & $2.3956 \cdot 10^{-2}$ \\
\hline 3 & $5.3521 \cdot 10^{-1}$ & $2.3520 \cdot 10^{-2}$ \\
\hline
\end{tabular}

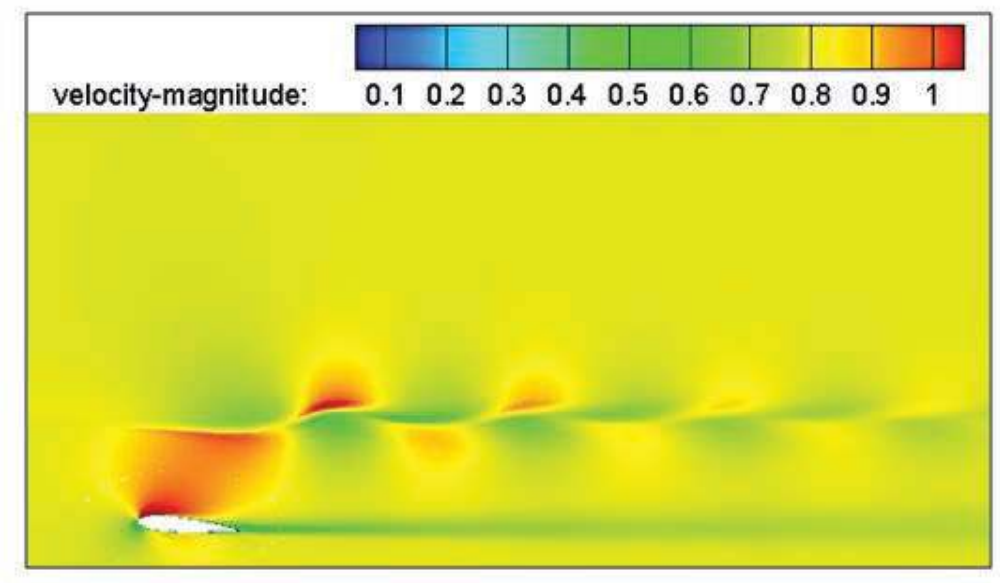

FIG. 8: Contour of velocity around the NACA0015 hydrofoil at $\mathrm{Fr}=0.57$ and $h / c=0.91$ 


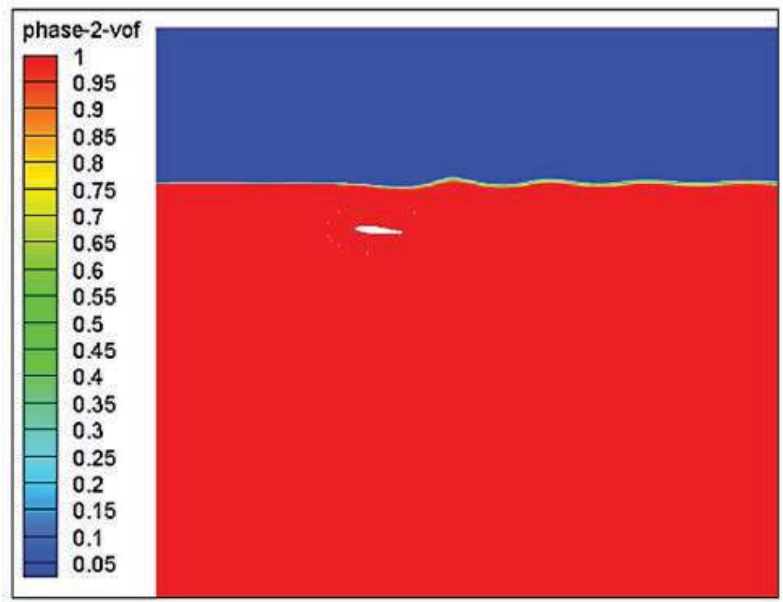

FIG. 9: Contour of volume fraction for the NACA0015 hydrofoil at $\mathrm{Fr}=0.57$ and $h / c=0.91$

\subsection{Analysis of 2D Hydrofoil with Cavitation}

The studied case is the NACA0015 hydrofoil at an angle of attack of $5^{\circ}$ and $8^{\circ}$, with chord length $c$ equal to $115 \mathrm{~mm}$, extending 2 chord lengths ahead of the leading edge and 4 chord lengths behind the trailing edge.

In this study, total 56,400 cells are used. To simulate the cavitating flows, a noncavitation computation is initially performed.

Figures 10 and 11 show the pressure coefficient profile under noncavitation conditions for two incidence angles $5^{\circ}$ and $8^{\circ}$. Distributions of the pressure coefficient are

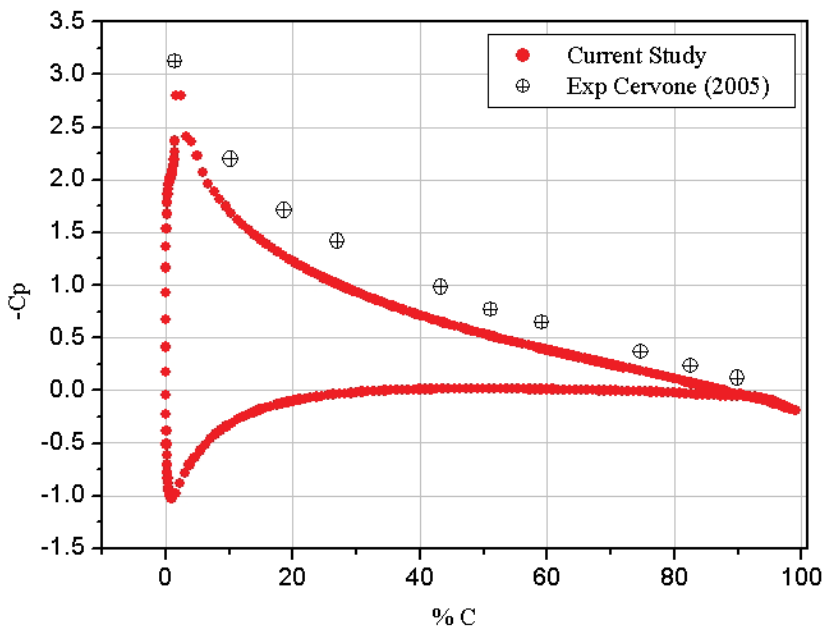

FIG. 10: Pressure coefficient around the NACA0015 hydrofoil under noncavitation conditions at an incidence angle of $8^{\circ}$ 


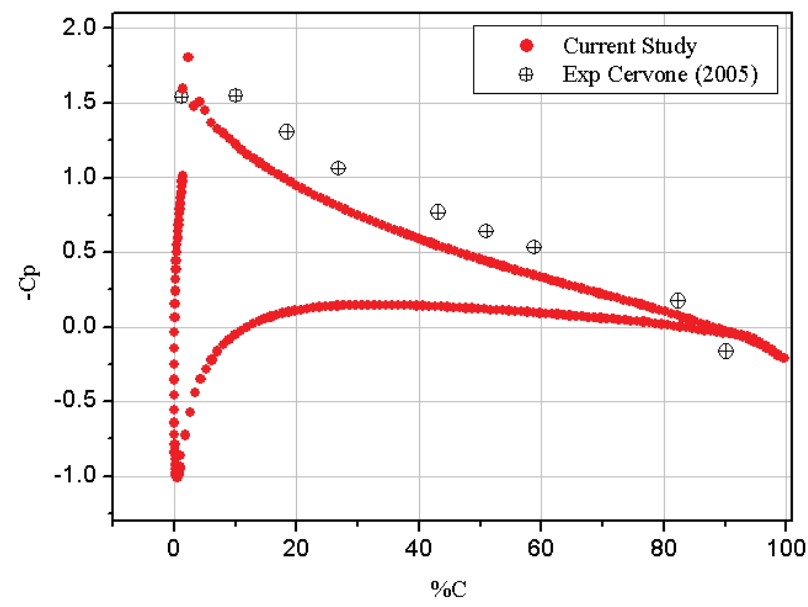

FIG. 11: Pressure coefficient around the NACA0015 hydrofoil under noncavitation conditions at an incidence angle of $5^{\circ}$

compared with experimental distributions along the suction side of the NACA0015 hydrofoil obtained by Cervone et al. (2005). This comparison shows good agreement between the calculated and experimental results.

The contour of the kinetic energy of turbulence shows that the $k-\varepsilon$ model is appropriate for this type of simulation (Fig. 12).

Steady cavitation flow over a NACA0015 hydrofoil section was predicted using the Schnerr and Sauer (2001) cavitation model. After analyzing Fig. 13, it can be con-

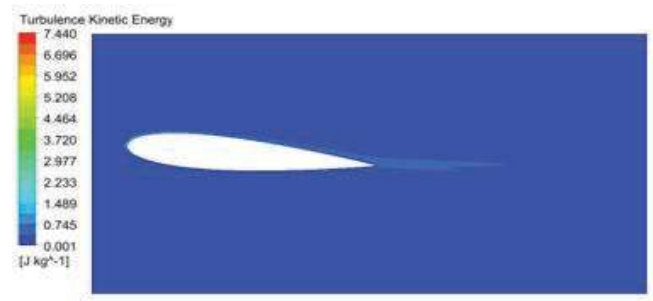

$\sigma=1.5$

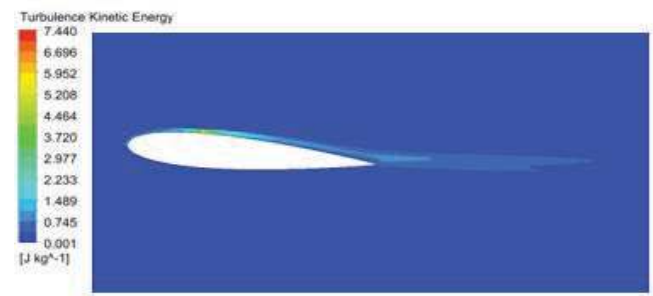

$\sigma=1.2$
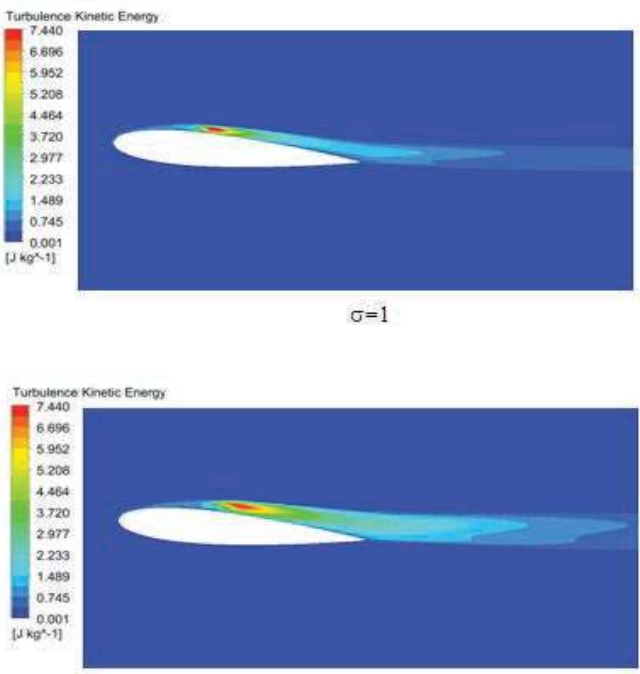

$\sigma=0.8$

FIG. 12: Contour of kinetic energy around the NACA0015 hydrofoil under cavitation conditions at an incidence angle of $5^{\circ}$ 


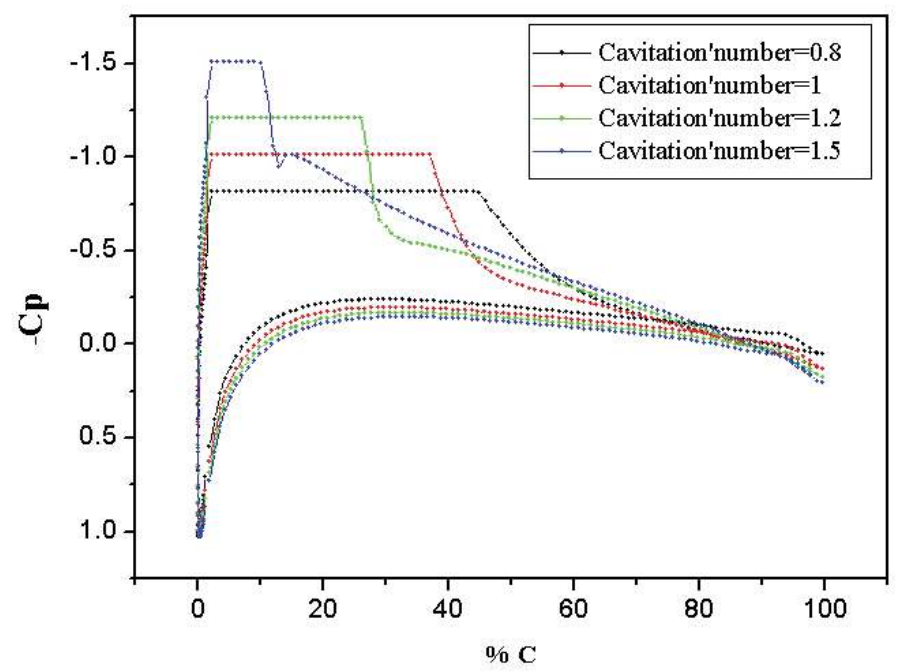

FIG. 13: Pressure coefficient around the NACA0015 hydrofoil under cavitation conditions at an incidence angle of $5^{\circ}$

cluded that the pressure ambient is decreased when the pressure on the upper surface decreases by exactly the same amount until the upper surface begins to cavitate. At this point, the pressure on the upper surface can decrease below the cavity pressure which is near the vapor pressure, so the shape of the pressure curve changes as cavitation develops, indicating the sheet cavity. The chosen cavitation model can predict the cavitation phenomena with high accuracy.

\subsection{Analysis of 2D Cavitating Flow around Hydrofoil Near the Free Surface}

To construct the computational domain, Gambit (Version 2.3.16) software is used. The geometry of the hydrofoil is created by using the NACA16-006 coordinates. To mesh the two-dimensional domain, it was divided into several regions in order to control the free surface and the hydrofoil boundary layer and wake areas where structured meshes are used, as shown in Fig. 14.

For computations of the cavitating flow near the free surface, first the NACA16-006 hydrofoil is used, where the chord is 1.0 and angle of attack is $4^{\circ}$, at submergence ratios $(\mathrm{h} / \mathrm{c})$ equal to 0.5 , the study is done for different cavitation numbers $\sigma=0.5,0.7,1,1.2,1.4$, and 1.6.

Firstly, the grid sensitivity is carried out by comparing the results for noncavitating flow. Five different grids are tested. The pressure distributions around the NACA16-006 hydrofoil and free surface elevation for $\alpha_{L}=0.5$ are presented respectively in Figs. 15 and 16 for different meshes. From these figures, it is observed that the differences were minimal between the second (83,904 cells) and fine mesh (181,803 cells). 


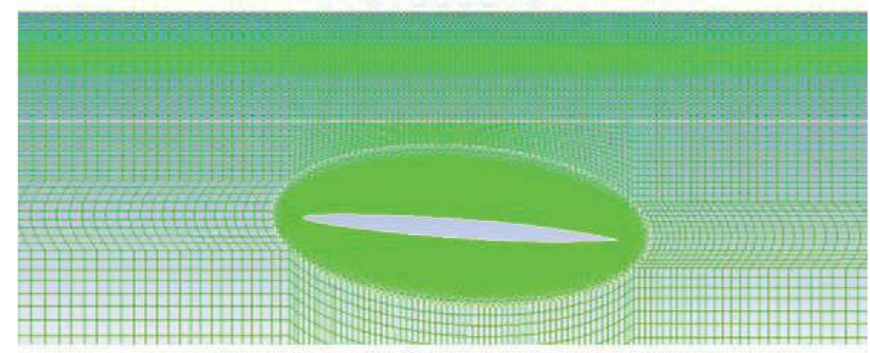

FIG. 14: Computational grid for the NACA16-006 hydrofoil

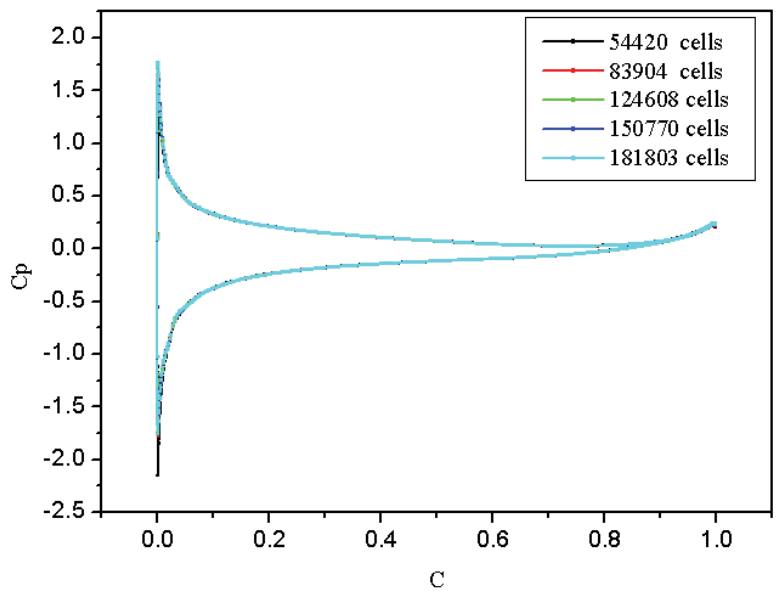

FIG. 15: Pressure distributions around the NACA16-006 hydrofoil for different meshes under noncavitation conditions at $h / c=0.5$ and an incidence angle of $4^{\circ}$

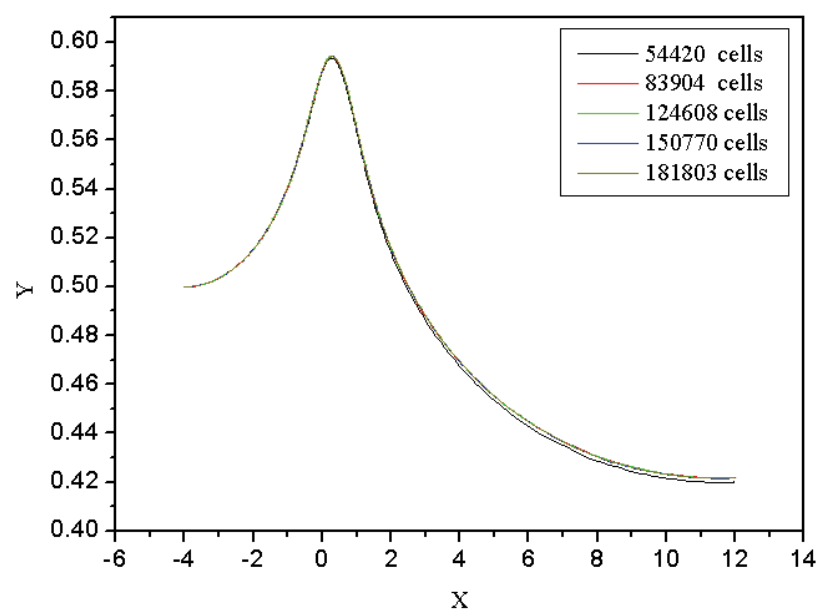

FIG. 16: Free surface elevation around the NACA16-006 hydrofoil for different meshes under noncavitation conditions at $h / c=0.5$ and an incidence angle of $4^{\circ}$ 
For this reason, the rest of the simulations were carried out considering the second resolution mesh $(83,904$ cells $)$.

For computation of the cavitating flow near the free surface, an iterative procedure is used. The iterative steps are described as follows:

1. Compute the flow field without cavitation and capture the free surface by using the VOF method. The computational domain has been divided at line $y / c=0.3$ (below the free surface) and separate the fluid in two.

2. Remove fluid above this line (save it under Case 1) and activate cavitation model of Schnerr and Sauer (2001), where the velocity distribution, turbulent kinetic energy, and turbulent dissipation rate on line $y / c=0.3$ and the static pressure distribution on the outlet boundary are specified as parts of boundary conditions.

3. Exclude the area occupied by the cavity which coincides with the contour line where the volume fraction $\alpha_{\mathrm{L}}$ takes the value of 1 as shown in Fig. 17.

4. Add fluid 1 (from Case 1) which is deleted in the first step. Declare the line for $y / c=0.3$ from two fluids as interface boundary. The pressure, velocity, kinetic energy, and dissipation on the cavity are specified as boundary conditions. These conditions are introduced on line for volume fraction $\alpha_{\mathrm{L}}=1$.

5. Compute the flow field and update the free surface by using the VOF method.

6. Repeat steps (1) to (4) until a proper convergence of the cavity shape and free surface is achieved, all steps are done in FLUENT (2014). The calculation is done without changing the mesh.

In Table 2, the lift and drag coefficients obtained during the first iteration with the free surface and those calculated during the first iteration of cavitation are given for

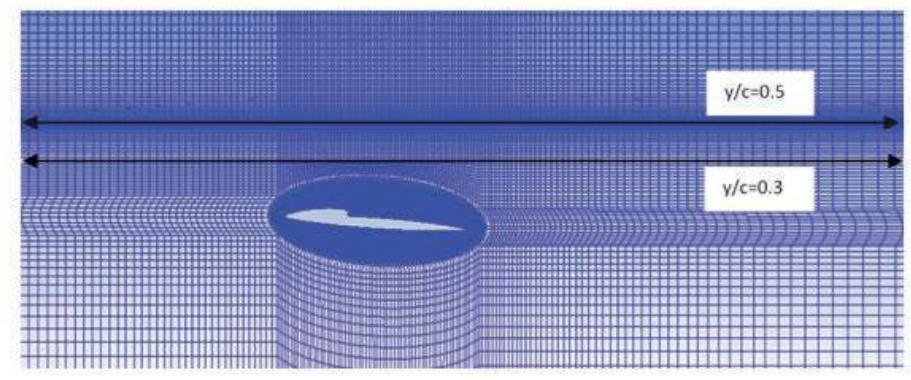

FIG. 17: The computational grid in the third step

TABLE 2: Force coefficients at an angle of attack of $4^{\circ}$ and $\sigma=1.8$

\begin{tabular}{|c|c|c|}
\hline & CL & CD \\
\hline Iteration 1 with a free surface & $2.98810^{-1}$ & $0.22710^{-1}$ \\
\hline Iteration 1 with cavitation & $2.9810^{-1}$ & $0.22710^{-1}$ \\
\hline
\end{tabular}


$\sigma=1.8$. These coefficients confirm that the conditions used during the first iteration with the free surface and which were introduced to the first iteration of cavitation (noncavitating flow for $\sigma=1.8$ ) are the same.

Figures 18 and 19 show, respectively, the convergence history of the free surface and length of cavity from different cavitation numbers $\sigma=0.5,0.7,1,1.2,1.4$, and 1.6. It is observed that the convergence is achieved for fourth first cavitation numbers in the second iteration, while for the rest cavitation numbers there is no variation for free surface elevation and length of cavity from all five iterations. The free surface is well converged after the first iteration. The convergence results show that the hydrofoil is partially cavitating at the leading edge and the cavity length is about $0.335 c$ for $\sigma=0.5$. A small cavity is for $\sigma=1.6$ where the length is $0.0046 c$. For all cavitation numbers, the maximum wave height about $0.10057 \mathrm{~m}$ appears at the location directly above the leading edge of the hydrofoil.

To predict the behavior of the cavitating flow around the NACA16-006 hydrofoil near the free surface for different cavitation numbers, an iterative procedure is used with minimum error to obtain the convergence results as shown in Fig. 20. The difference from wave height obtained in the current study is less than that calculated by $\mathrm{Wu}$ and Chen (2016).

Steady behavior of cavitation contours of vapor fraction for $\sigma=0.5$ is presented in Fig. 21 where the sheet cavitation occurs. In this condition, vapor covers the tip of hydrofoil and vortex is created below the end of the cavity, as shown in Fig. 22, this re-entrant jet covers the surface between the cavity and hydrofoil and eventually causes the cavity to separate from the hydrofoil surface in unsteady flow.

The present method was finally applied for a supercavitating profile as shown in Fig. 23, at different cavitation numbers with the same conditions as mentioned above.

Table 3 presents a variation of lift and drag coefficients. It is clear that when the cavitation increases, the lift increases, the drag increases too but slightly. This is the principle of supercavitation.

Figures 24 and 25 show, respectively, the free surface and cavity length around the supercavitating hydrofoil at an angle of attack of $4^{\circ}$. For this number, the sheet cavity is generated near the leading edge and is attached to the surface of the foil. Its length is about $0.60 c$, and wave height is about $0.28 \mathrm{~m}$.

\section{CONCLUSIONS}

The wave generated by flow with cavitation around a shallowly submerged hydrofoil near the free surface is simulated in this research.

First, flow with free surface around NACA0012 and NACA0015 hydrofoils for different submergence depths at $\mathrm{Fr}=0.5711$ is simulated by solving the RANS equations.

Second, cavitating flow is simulated using NACA0015 section for different cavitation numbers. 


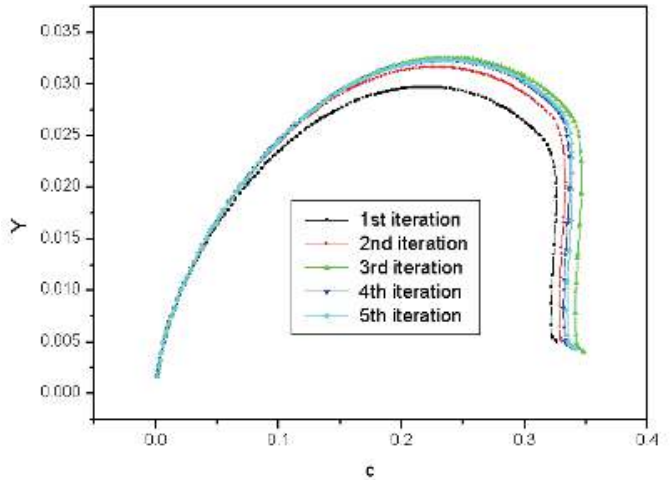

(a)

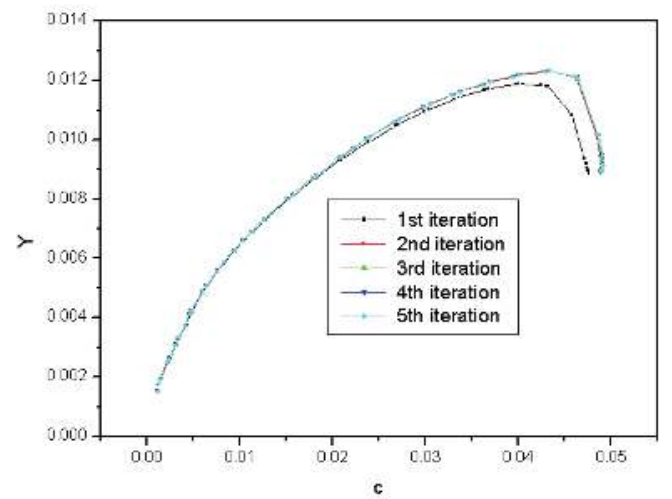

(c)

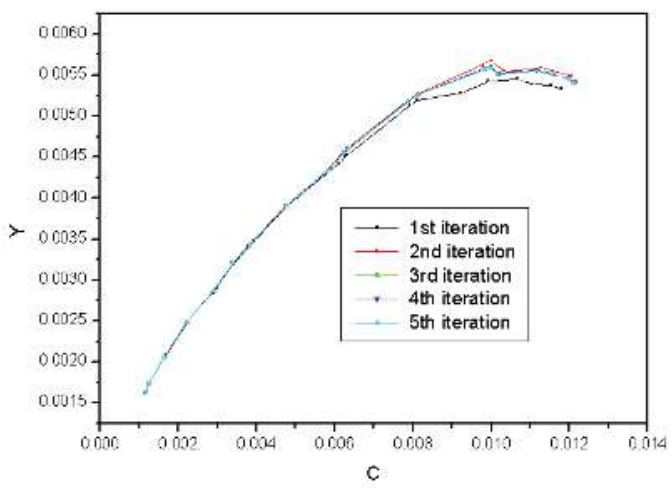

(e)

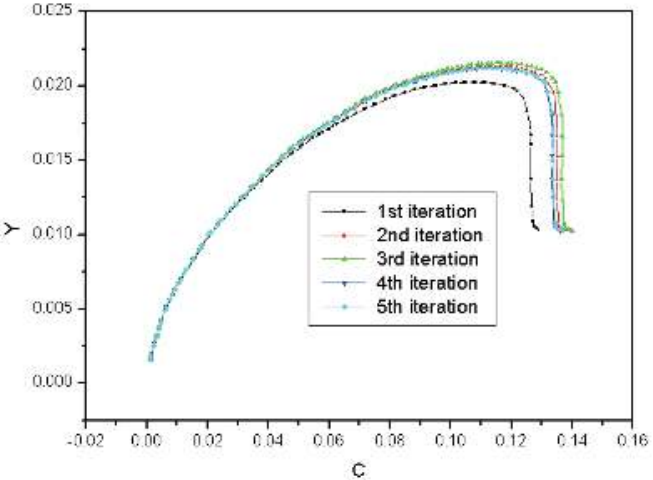

(b)

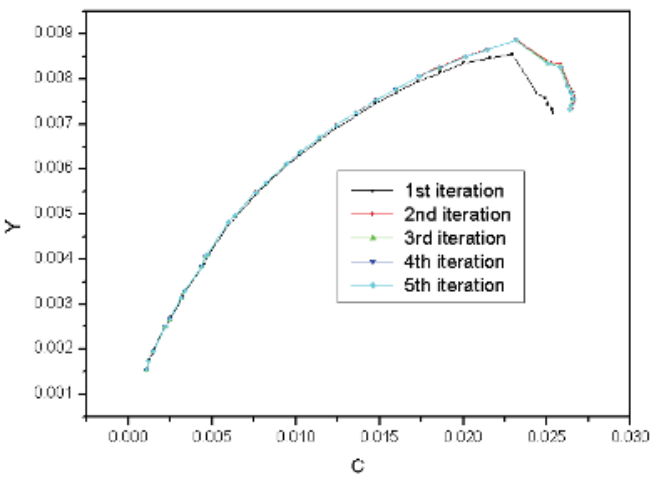

(d)

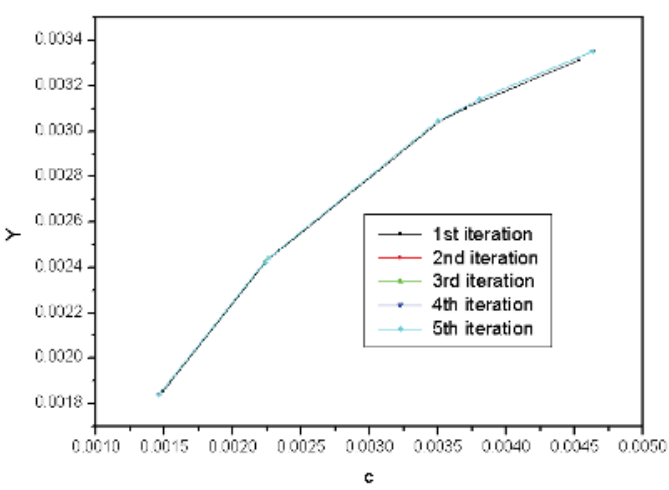

(f)

FIG. 18: Convergence history of cavity length for different cavitation numbers at an incidence angle of $4^{\circ}$ 


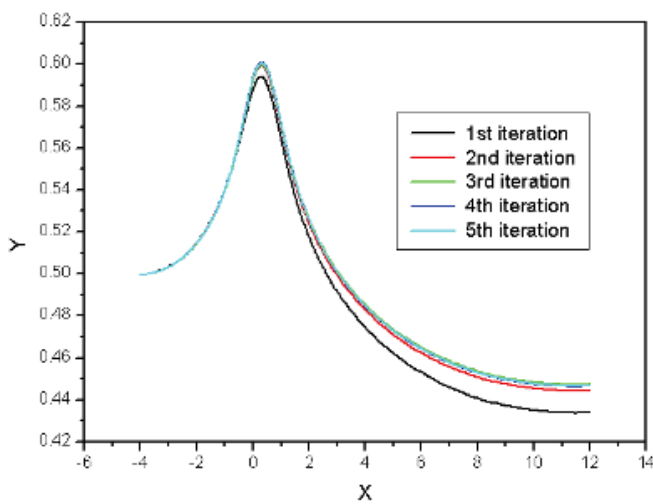

(a)

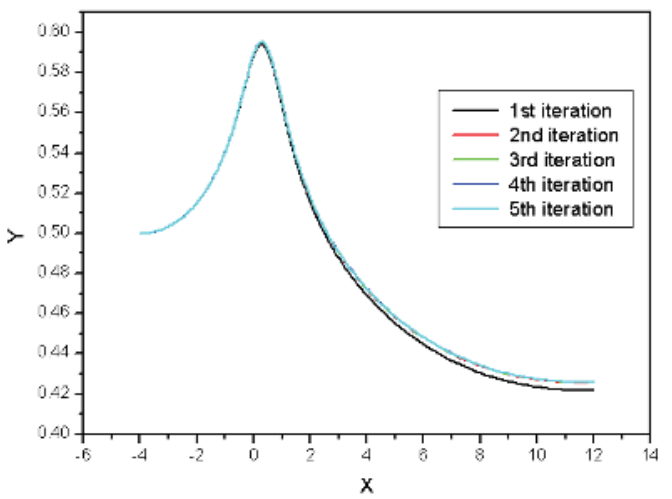

(c)

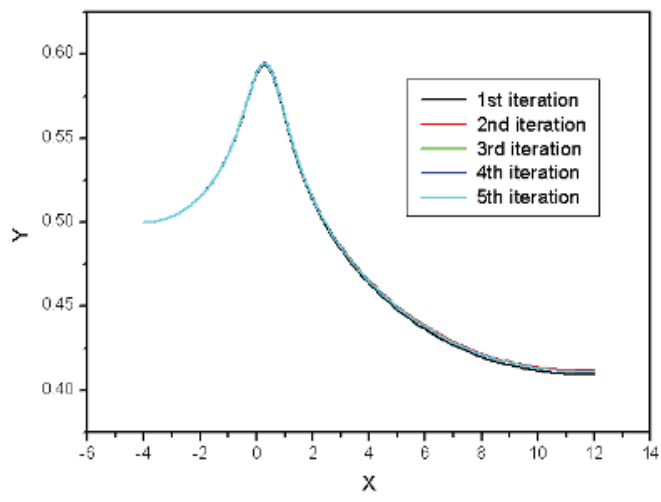

(c)

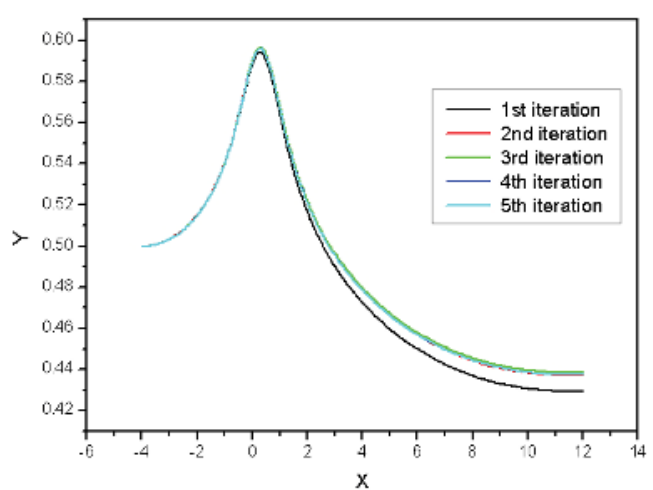

(b)

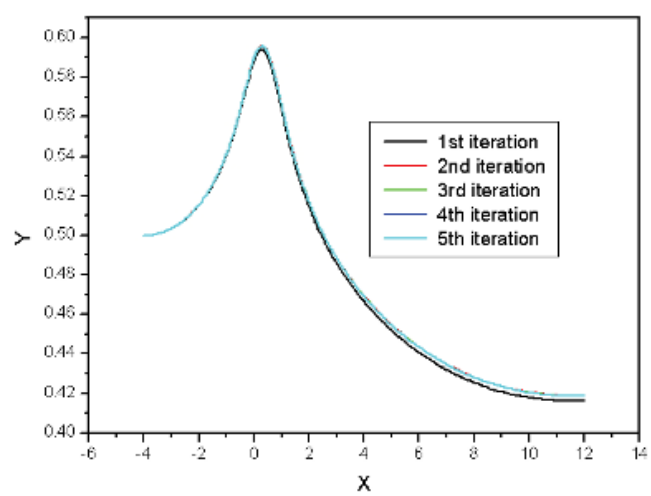

(d)

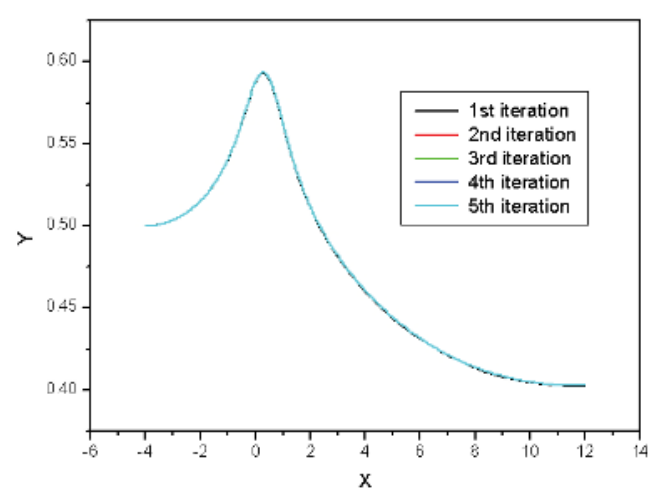

(d)

FIG. 19: Convergence history of the free surface for different cavitation numbers at an incidence angle of $4^{\circ}$ 


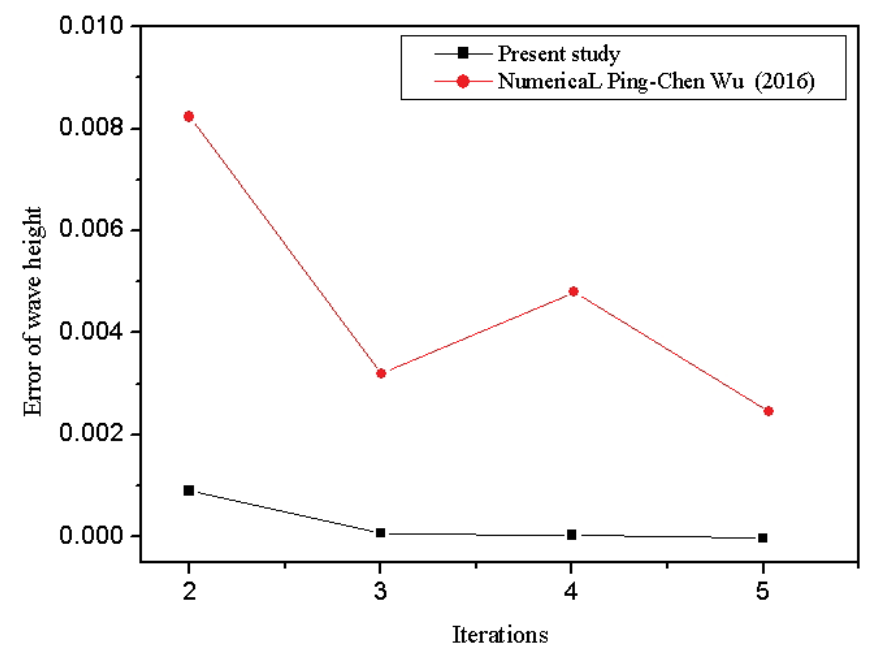

FIG. 20: Comparison between error of wave height at an incidence angle of $4^{\circ}$ and $\sigma=1$

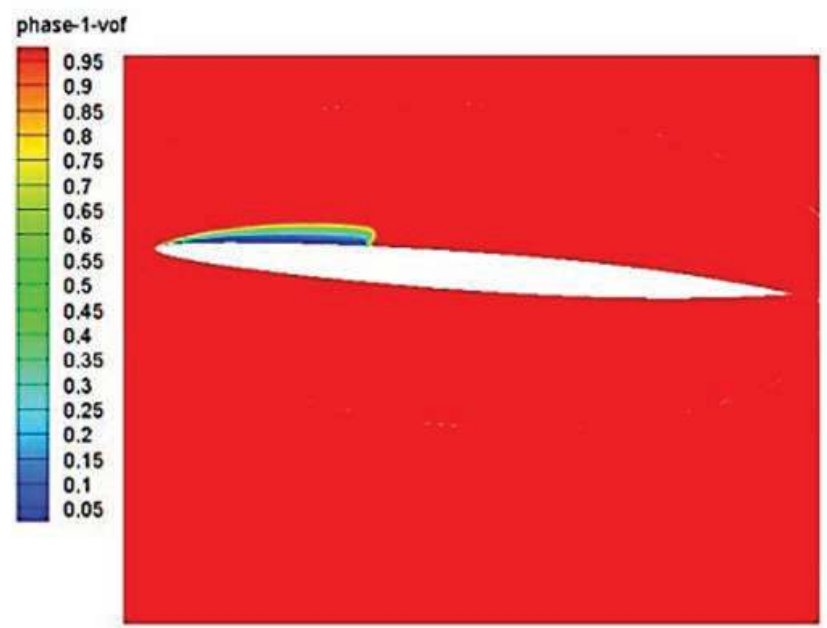

FIG. 21: Vapor fraction distribution around the NACA16-006 hydrofoil at $\sigma=0.5$ and an incidence angle of $4^{\circ}$

Finally, an iterative numerical procedure is developed in this study, to simulate cavitating flow with the effect of free surface around the NACA16-006 hydrofoil and supercavitating foil.

From the above results and discussions, it can be concluded that:

- The wave profiles along the submerged NACA0012 hydrofoil agree well with the available experimental results, which validates our simulations for these types of cases. 


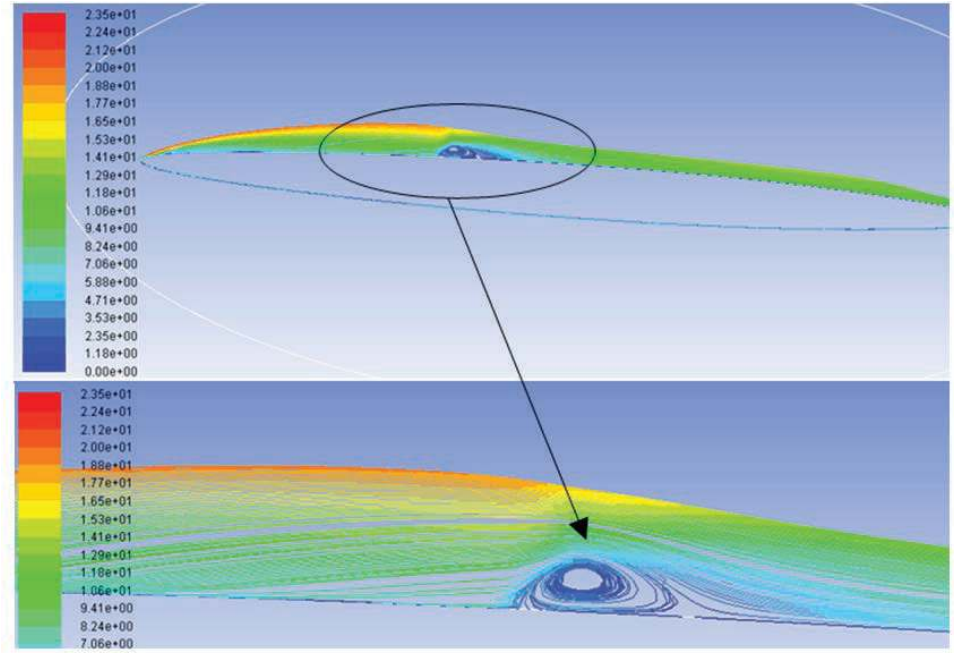

FIG. 22: Velocity distribution around the NACA16-006 hydrofoil at $\sigma=0.5$ and an incidence angle of $4^{\circ}$

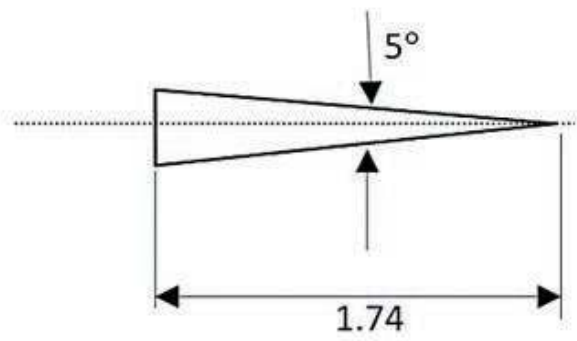

FIG. 23: Hydrofoil section tested supercavitating foil

- The simulations of the noncavitating NACA0015 hydrofoil under the free surface confirmed the lift and drag behaviors as the foil approaches the free surface.

- An iterative procedure to combine sheet cavitation and the free surface effects has been developed and tested for the NACA16-006 hydrofoil. The convergence results can satisfactorily predict shape of cavity generated by the flow around hydrofoil moving beneath the free surface for a steady case. The used iterative method is then successfully applicable to predict the shape of a cavity generated by the flow around hydrofoil moving beneath the free surface at least in a steady-state case.

- The verified iterative procedure has finally be successfully applied for the case of a supercavitating foil. 
TABLE 3: Force's coefficients for a supercavitating profile at an incidence angle of $4^{\circ}$

\begin{tabular}{|c|c|c|}
\hline Cavitation Number & CL & CD \\
\hline$\sigma=0.5$ & 0.687 & 0.083 \\
\hline$\sigma=0.8$ & 0.635 & 0.082 \\
\hline$\sigma=1$ & 0.614 & 0.081 \\
\hline$\sigma=1.2$ & 0.597 & 0.080 \\
\hline$\sigma=2$ & 0.531 & 0.076 \\
\hline
\end{tabular}

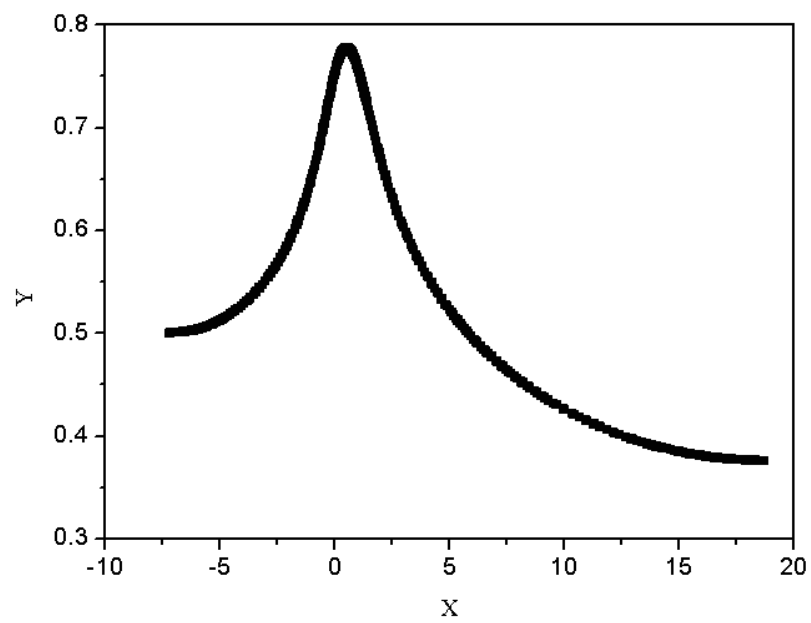

FIG. 24: Free surface elevation for a supercavitating profile at $h / c=0.5, \sigma=0.5$, and an incidence angle of $4^{\circ}$

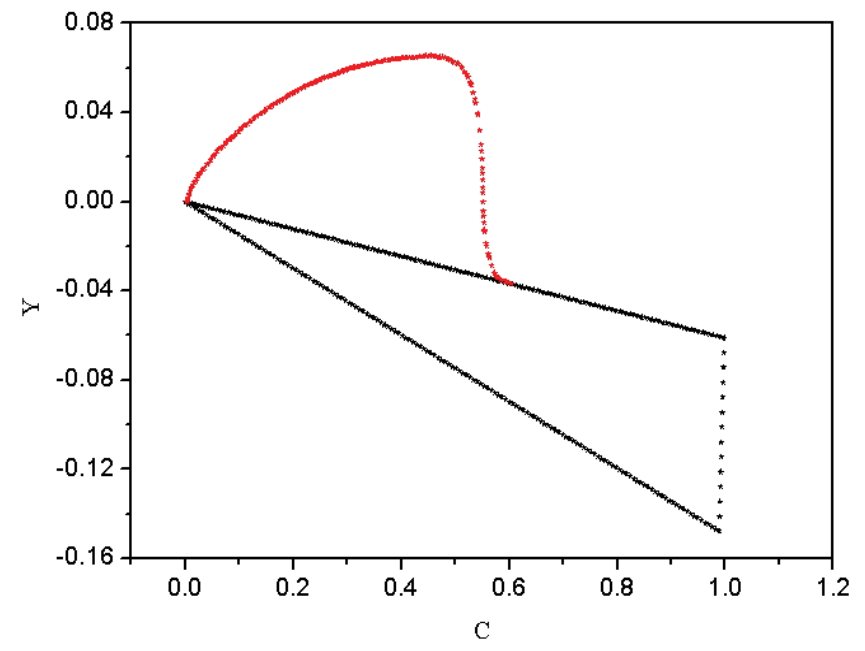

FIG. 25: Cavity length for a supercavitating profile $\sigma=0.5$, an incidence angle of $4^{\circ}$, and $h / c=0.5$ 


\section{REFERENCES}

Asnaghi, A., Jahanbakhsh, E., and Seif, M.S., Unsteady Multiphase Modeling of Cavitation around NACA0015, J. Marine Sci. Technol., vol. 18, no. 5, pp. 689-696, 2010.

Cervone, A., Bramanti, C., Rapposelli, E., and d'Agosino, L., Thermal Cavitation Experiments on a NACA0015 Hydrofoil, J. Fluids Eng., vol. 128, no. 2, pp. 326-331, 2005.

Dular, M., Bachert, R., Stoffel, B., and Širok, B., Experimental Evaluation of Numerical Simulation of Cavitating Flow around Hydrofoil, E. J. Mech. B/Fluids, vol. 24, no. 4, pp. 522-538, 2005.

Duncan, J.H., The Breaking and Non-Breaking Wave Resistance of a Two-Dimensional Hydrofoil, J. Fluid Mech., vol. 126, pp. 507-520, 1983.

Faltinsen, O.M., Hydrodynamics of High-Speed Marine Vehicles, New York: Cambridge-USA, 2005.

Farmer, J., Martinelli, L., and Jameson, A., A Fast Multigrid Method for Solving Incompressible Hydrodynamic Problems with Free Surfaces, J. AIAA, vol. 32, no. 6, pp. 1175-1182, 1994.

Giesing, J.P. and Smith, A.M.O., Potential Flow about Two-Dimensional Hydrofoils, J. Fluid Mech., vol. 28, no. 1, pp. 113-129, 1967.

Hino, T., Martinelli, L., and Jameson, A., Finite-Volume Method with Unstructured Grid for Free Surface Flow Simulations, Proc. of 6th Int. Conf. on Numerical Ship Hydrodynamics, Iowa, USA, 1993.

Hirt, C.W. and Nichols, B.D., Volume of Fluid (VOF) Method for the Dynamics of Free Boundaries, J. Comput. Phys., vol. 39, no. 1, pp. 201-225, 1981.

Jin, M.S., Ha, C.T., and Park, W.G., Numerical Study of Ventilated Cavitating Flows with Free Surface Effects, J. Mech. Sci. Technol., vol. 27, no. 12, pp. 3683-3691, 2013.

Kim, J. and Lee, J.S., Numerical Study of Cloud Cavitation Effects on Hydrophobic Hydrofoils, Int. J. Heat Mass Transf., vol. 83, pp. 591-603, 2015.

Kunz, R.F., Boger, D.A., Stinebring, D.R., Chyczewski, T., Gibeling, H., Venkateswarn, S., and Govindan, T.R., Preconditioned Navier-Stokes Method for Two-Phase Flows with Application to Cavitation Prediction, J. Computers Fluids, vol. 29, no. 8, pp. 849-875, 2000.

Kwag, S.H., Computation of Water and Air Flow with Submerged Hydrofoil by Interface Capturing Method, Int. J. KSME, vol. 14, no. 7, pp. 789-795, 2000.

Li, Z. and Terwisga, T.V., On the Capability of a RANS Method to Assess Cavitation Erosion Risk on a Hydrofoil, Proc. of 8th Int. Symp. on Cavitation, Singapore, August 13-16, 2012.

Li, Z., Mathieu, P., and Terwisga, T.V., A Numerical Study of Steady and Unsteady Cavitation on 2D Hydrofoil, J. Hydrodynamics, vol. 22, no. 5, pp. 770-777, 2010.

Mashud, K.M., Prasad, B., and Rahman, N., Numerical Simulation of Free Surface Water Wave for the Flow around NACA0015 Hydrofoil Using the Volume of Fluid (VOF) Method, J. Ocean Eng., vol. 78, pp. 89-94, 2014.

Merkle, C.L., Feng, J.Z., and Buelow, P.E.O., Computational Modeling of the Dynamics of Sheet Cavitation, Proc. of 3rd Int. Conf. on Cavitation, pp. 307-311, 1998.

Muzaferija, S. and Perie, M., Computation of Free Surface Flows Using Finite Volume Method and Moving Grids, J. Numer. Heat Transfer, Fundam., vol. 32, no. 4, pp. 369-384, 1997.

Prasad, B., Hino, T., and Suzuki, K., Numerical Simulation of Free Surface Flows around Shallowly Submerged Hydrofoil by Open FOAM, J. Ocean Eng., vol. 102, pp. 87-94, 2015.

Roohi, E., Zahiri, A.P., and Passandideh, F.M., Numerical Simulation of Cavitation around a Two-Dimensional Hydrofoil Using VOF Method and LES Turbulence Model, J. Appl. Math. Model., vol. 37, no. 9, pp. 6469-6488, 2013. 
Sauer, J., Instationär kavitierende Strömungen-Ein neues Modell, basierend auf Front Capturing (VoF) und Blasendynamik, PhD, University of Karlsruhe, 2000.

Schnerr, G.H. and Sauer, J., Physical and Numerical Modeling of Unsteady Cavitation, Proc. of 4th Int. Conf. on Multiphase Flow, New Orleans, USA, 2001.

Singhal, A.K., Athavale, M.M., Li, H., and Jiang, Y., Mathematical Basis and Validation of the Full Cavitation Model, J. Fluids Eng., vol. 124, no. 3, pp. 617-624, 2002.

Tarafder, M.S., Saha, G.K., and Mehedi, S.T., Analysis of Potential Flow around 3-Dimensional Hydrofoils by Combined Source and Dipole Based Panel Method, J. Marine Sci. Technol., vol. 18, no. 3, pp. 376-384, 2010.

Wu, P.C. and Chen, J.H., Numerical Study on Cavitating Flow due to a Hydrofoil near a Free Surface, J. Ocean Eng. Sci., vol. 1, no. 3, pp. 1-8, 2016.

Xie, N., and Vassalos, D., Analysis of 3D Hydrofoil under Free Surface, J. Ocean Eng., vol. 34, no. 8, pp. 1257-1264, 2007.

Zwart, P., Gerber, A.G., and Belamri, T., A Two-Phase Model for Predicting Cavitation Dynamics, Proc. of 8th Int. Conf. on Multiphase Flow, Yokohama, Japan, 2004. 